\title{
Biochemical Analysis of Three Biological Fluids and its Response to Non-Surgical Periodontal Therapy in Pre and Postmenopausal Women with Periodontitis
}

\author{
Jammula Surya Prasanna, Chinta Sumadhura \\ Department of Periodontics, Panineeya Institute of Dental Sciences and Research Centre, Hyderabad, India
}

Objectives: Periodontitis is a common chronic inflammatory disease characterized by the destruction of the supporting structures of the teeth. The stages of menopause also worsen inflammatory condition. Biomarkers from biological fluids can be used as a diagnostic indicator to correlate these two conditions of present and future disease activity. The aim of the present study was to evaluate the neopterin levels in three biological fluids obtained from pre- and postmenopausal women with periodontitis following non-surgical periodontal therapy (NSPT, that is, scaling).

Methods: This was a cross-sectional interventional study. Thirty women, aged 40-60 years, with periodontitis were selected according to their menstrual history. They were divided into the pre- and postmenopausal groups, with each group including 15 participants. The neopterin levels were measured in both groups at baseline and 3 months after NSPT. Intergroup comparison and percentage decrement analysis were performed using the independent sample $t$ test, and intragroup comparison was performed using the paired $t$ test.

Results: There were statistically significant reductions in the mean values of saliva, urine, and plasma from baseline to 3 months after NSPT in the groups. Intergroup comparison showed no significant values in the postmenopausal group, and a significant reduction was seen in the mean values was seen in the mean values.

Conclusions: : Neopterin levels decreased at 3 months after NSPT in both the groups, suggesting that NSPT can be a gold standard therapy and that the neopterin level could be a indicator to identify periodontal destruction.

Key Words: Biomarkers, Inflammation, Menopause, Neopterin, Periodontitis

\section{INTRODUCTION}

The main etiology of the periodontal disease is the plaque which leads to the host-microbial interactions and can cause the destruction of the periodontal ligament and alveolar bone. This destruction results from the recruitment of the host cells [1]. Some of the biomarkers act as a diagnostic indicator of present and future periodontal disease by measuring the substances in body fluids that correlate with the level of disease activity and tissue destruction. A biomarker is a feature or facet that can be used to measure the progress of dis- ease or the effects of treatment [2].

Neopterin is a catabolic product of guanosine triphosphate and belongs to the chemical group pteridines. It is synthesized by human macrophages upon stimulation with the cytokine interferon-gamma and is indicative of a pro-inflammatory immune status. Thus it serves as a marker of cellular immune system activation [3]. Neopterin concentration increases with increasing severity of periodontal disease in diverse body fluids like urine, saliva, and plasma. Hence neopterin can be considered as an important inflammatory marker in periodontal disease as well as other systemic

Received: September 16, 2018 Revised: November 2, 2019 Accepted: November 3, 2019

Address for Correspondence: Jammula Surya Prasanna, Department of Periodontics, Panineeya Institute of Dental Sciences and Research Centre, Road no-5, Kamala Nagar, Dilsucknagar, Hyderabad 500060, India

Tel: 91-9440387830, E-mail: prasanna.parupalli@gmail.com, ORCID: https://orcid.org/0000-0003-3773-3673 
diseases. It is important to recognize the inflammatory changes well in advance so that preventive measures can be taken in the early stages. It has been found that non-surgical periodontal therapy (NSPT) reduces the inflammatory burden and restores the health of the periodontium and systemic health [4]. Even though pre- and postmenopause both are inflammatory in nature, literature is saying that more serious imperilment changes occurs in postmenopause. In this study an attempt was made to catch a glimpse of the inflammation decline by measuring neopterin levels and its response to NSPT in pre- and postmenopausal women.

\section{MATERIALS AND METHODS}

Total thirty female patients who were meeting the selection criteria between 40 and 60 years of age were included in this study. All of them were explained about the study design and the written informed consent was obtained before the procedure was carried out. This study was approved by the institutional ethical committee (Reg. No.- ECR/267/Indt/AP/2016). This study was also registered under clinical trial (https://clinicaltrials. gov; the reg no is NCT02357745). According to 1999 American Academy of Periodontology (AAP) classification periodontitis patients were recruited in the study [5]. All the subjects were examined by gynecologist. Depending on the menstrual history, all the patients were divided into two groups with each group comprising of 15 individuals; Group I: 15 premenopausal women with chronic periodontitis, Group II: 15 postmenopausal women with chronic periodontitis.

Inclusion criteria: 1) Patients suffering from chronic moderate periodontitis $\geq 4 \mathrm{~mm}$ pocket depth or $\geq 3$ $\mathrm{mm}$ loss of attachment. 2) Patients should have at least 15 natural teeth remaining. 3) Nonsmokers. 4) Systemically healthy from past 6 months. Exclusion criteria: 1) Present or past smokers. 2) With gross oral pathology or tumors. 3) Patients on long-term steroid medication and if using any other medications for any other systemic diseases. 4) Undergoing hormone replacement therapy. 5) Patients underwent any dental treatment for past 6 months. 6) Any systemic disorders or any medications that affect the periodontal status were excluded from the study.

Total thirty patients were examined and samples collected at baseline and at 3 months intervals after NSPT to assess the neopterin values, patient selection criteria explained in (Fig. 1). Strict instructions were given not to rinse with mouthwash on the day of sample collection.

\section{Sample collection and preparation}

Plasma, saliva, and urine samples from the patients were collected for detection of the neopterin levels at baseline and 3 months after the treatment. All the collected samples were kept away from direct light, and stored at $-20^{\circ} \mathrm{C}$ until assayed.

\section{Plasma}

Five $\mathrm{mL}$ of peripheral venous blood was drawn from brachial plexus through vein puncture method. Whole blood was collected in purple topped cover tubules (EDTA tubes, $4 \mathrm{~mL}$; CML Biotech (P) Ltd., Kerala, India). Obtained by centrifuging at $3000 \times \mathrm{g}$ for $10 \mathrm{~min}$ utes in a centrifuge (R-4C; REMI Laboratory Instruments, Mumbai, India), immediately liquid component, plasma was transferred into a clean polypropylene tube (Ria Vials; Tesca Technologies Pvt. Ltd., Jaipur, India) using a Pasteur pipette (Ajosha Bio Teknik Pvt. Ltd., Mumbai, India). These tubes were stored at $-20^{\circ} \mathrm{C}$ until used.

\section{Saliva}

One milliliter of whole saliva sample was collected by unstimulated passive drool in a sterile disposable plastic container (Polypropylene tubes, 0-15 mi; Thermo Fisher Scientific, Waltham, MA, USA). The patients were asked to collect saliva in their mouth by avoiding swallowing until a small amount of saliva was collected. Then the patients tilted their head forward allowing the saliva to drool passively. Patients were instructed not to brush or eat 8 hours before collection of the samples and strictly instructed not to use any mouth rinses. No dental examination was carried out 48 hours prior to saliva collection. Samples were centrifuged to get clear saliva.

\section{Urine}

First urine sample was collected in the morning and was immediately enveloped in tin foil to protect them from the light and stored at $-20^{\circ} \mathrm{C}$ until measurement. No dietary recommendations were described prior to urine collection. Samples were diluted according to protocol prior to measurement. 


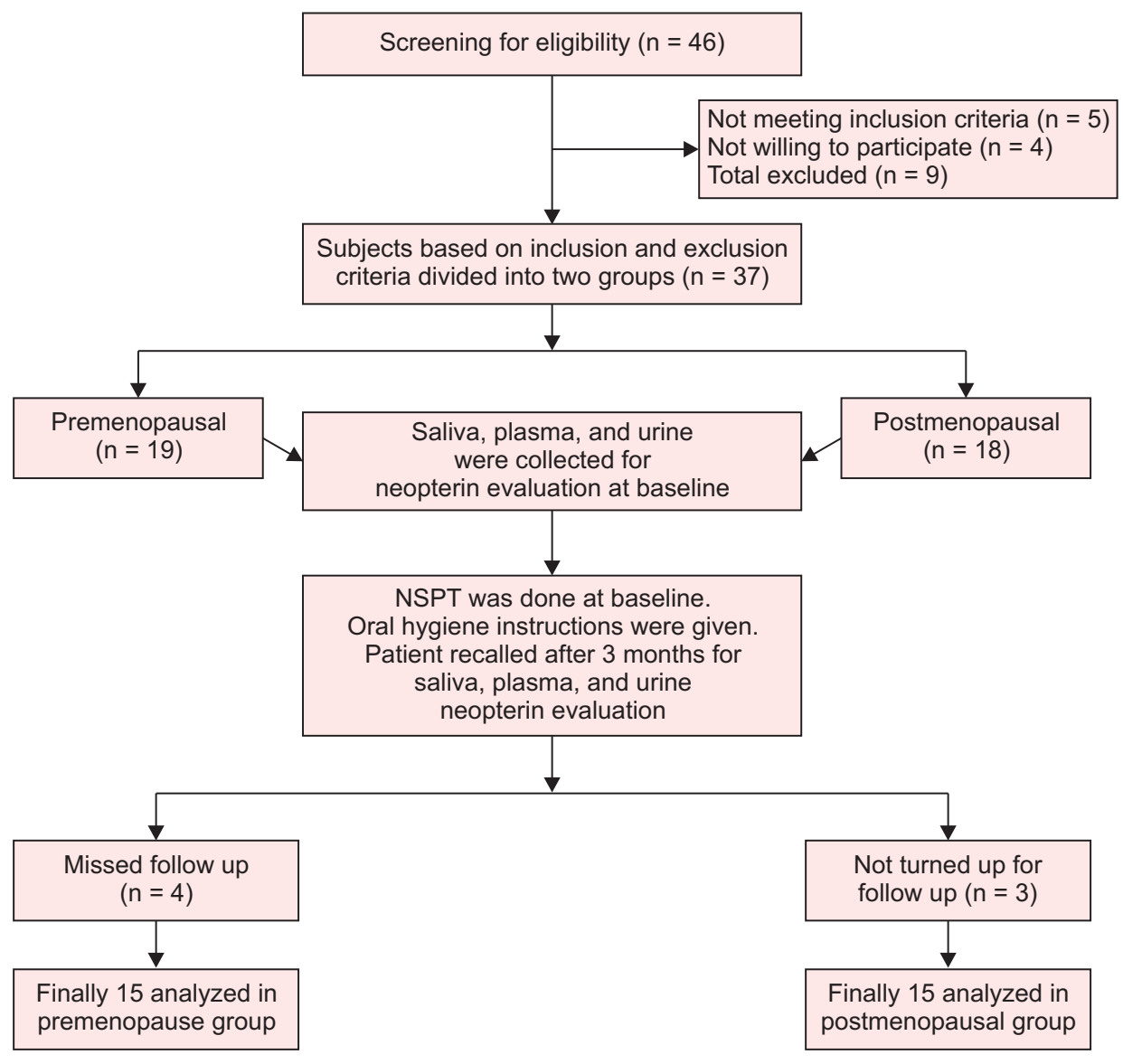

Fig. 1. Patient selection criteria. Consort flow chart. NSPT: non-surgical periodontal therapy.

\section{Biochemical analysis}

\section{Immunological assay}

Done with Neopterin ELISA Kit (Alpha Diagnostic Intl, San Antonio, TX, USA) for neopterin estimation, each sample was centrifuged at $10,600 \times \mathrm{g}$ for $10 \mathrm{~min}$ utes at $4^{\circ} \mathrm{C}$. Two hundred $\mu \mathrm{L}$ ethanol was added to 100 $\mu \mathrm{L}$ of sample to precipitate the proteins and vortexes for 1 minute. The supernatant in each sample was collected for estimation after centrifugation.

The observations recorded were subjected to statistical analysis using IBM SPSS version 21 software (IBM Co., Armonk, NY, USA). Intergroup comparison and percentage decrement was done by using independent sample $t$ test and intra group comparison was done by paired $t$ test. $P$ value $<0.05$ is considered as statistically significant.

\section{RESULTS}

When compared premenopausal group, all the parameters showed a statistically significant reduction from baseline to 3 months after treatment. Urine neopterin levels have reduced from $304.91 \pm 60.92 \mu \mathrm{mol} /$ $\mathrm{mol}$ to $265.57 \pm 54.57 \mu \mathrm{mol} / \mathrm{mol}$. The saliva neopterin levels have reduced from $13.63 \pm 1.55 \mathrm{nmol} / \mathrm{L}$ to $6.69 \pm$ $1.24 \mathrm{nmol} / \mathrm{L}$. The plasma neopterin levels have reduced from $11.72 \pm 1.51 \mathrm{nmol} / \mathrm{L}$ to $6.95 \pm 0.95 \mathrm{nmol} / \mathrm{L}$ from baseline to 3 months after treatment (Table 1).

Even in the postmenopausal group statistically significant reduction from baseline to 3 months was seen. The urine neopterin levels have reduced from 391.22 $\pm 61.98 \mu \mathrm{mol} / \mathrm{mol}$ to $290.45 \pm 52.48 \mu \mathrm{mol} / \mathrm{mol}$. The saliva neopterin levels have reduced from $15.61 \pm 1.83$ $\mathrm{nmol} / \mathrm{L}$ to $7.05 \pm 1.41 \mathrm{nmol} / \mathrm{L}$. The plasma neopterin levels have reduced from $13.52 \pm 2.51 \mathrm{nmol} / \mathrm{L}$ to 7.23 $\pm 1.09 \mathrm{nmol} / \mathrm{L}$ (Table 2). When compared these values in between two groups, at baseline neopterin levels was shown a statistically significant reduction. The $P$ values of urine, saliva, and plasma were $0.001,0.003$, and 0.02 , respectively (Table 3 ). At the same time, when these values were correlated in between two groups at 3 months after NSPT showed insignificant results (Table $4)$. 
Table 1. Comparison of the premenopausal group at baseline and 3 months

\begin{tabular}{|c|c|c|c|c|c|c|}
\hline Premenopausal & Number & $\begin{array}{l}\text { Mean } \pm \text { standard } \\
\text { deviation }\end{array}$ & $\begin{array}{c}\text { Mean difference } \\
\text { (95\% confidence interval) }\end{array}$ & $t$ & $\begin{array}{l}\text { Degrees of } \\
\text { freedom }\end{array}$ & $P$ value \\
\hline Urine ( $\mu \mathrm{mol} / \mathrm{mol}$; creatinine) & & & $39.34(3.96-74.73)$ & 2.39 & 14 & $0.032^{\mathrm{a}}$ \\
\hline Baseline & 15 & $304.91 \pm 60.92$ & & & & \\
\hline 3 months & 15 & $265.57 \pm 54.57$ & & & & \\
\hline Saliva (nmol/L) & & & $6.93(5.67-8.19)$ & 11.81 & 14 & $<0.001^{\mathrm{a}}$ \\
\hline Baseline & 15 & $13.63 \pm 1.55$ & & & & \\
\hline 3 months & 15 & $6.69 \pm 1.24$ & & & & \\
\hline Plasma (nmol/L) & & & $4.77(3.77-5.77)$ & 10.20 & 14 & $<0.001^{\mathrm{a}}$ \\
\hline Baseline & 15 & $11.72 \pm 1.51$ & & & & \\
\hline 3 months & 15 & $6.95 \pm 0.95$ & & & & \\
\hline
\end{tabular}

Paired $t$ test.

${ }^{\text {a }} P<0.05$ is statistically significant.

Table 2. Comparison of the postmenopausal group at baseline and 3 months

\begin{tabular}{|c|c|c|c|c|c|c|}
\hline Postmenopausal & Number & $\begin{array}{l}\text { Mean } \pm \text { standard } \\
\text { deviation }\end{array}$ & $\begin{array}{c}\text { Mean difference } \\
\text { (95\% confidence interval) }\end{array}$ & $t$ & $\begin{array}{l}\text { Degrees of } \\
\text { freedom }\end{array}$ & $P$ value \\
\hline Urine ( $\mu \mathrm{mol} / \mathrm{mol}$; creatinine) & & & $100.77(47.63-153.91)$ & 4.07 & 14 & $0.001^{\circ}$ \\
\hline Baseline & 15 & $391.22 \pm 61.98$ & & & & \\
\hline 3 months & 15 & $290.45 \pm 52.48$ & & & & \\
\hline Saliva (nmol/L) & & & $8.56(7.50-9.62)$ & 17.27 & 14 & $<0.001^{\mathrm{a}}$ \\
\hline Baseline & 15 & $15.61 \pm 1.83$ & & & & \\
\hline 3 months & 15 & $7.05 \pm 1.41$ & & & & \\
\hline Plasma (nmol/L) & & & $6.29(4.99-7.58)$ & 10.44 & 14 & $<0.001^{\circ}$ \\
\hline Baseline & 15 & $13.52 \pm 2.51$ & & & & \\
\hline 3 months & 15 & $7.23 \pm 1.09$ & & & & \\
\hline
\end{tabular}

Paired $t$ test.

${ }^{\mathrm{a}} P<0.05$ is statistically significant.

The intergroup comparison of these values from baseline to 3 months showed that the differences in the levels of neopterin between urine and saliva were statistically significant $(P$ value $<0.05)$, urine $(P=0.048)$ and saliva $(P=0.04)$, whereas plasma neopterin levels were not statistically significant (Table 5, Fig. 2).

\section{DISCUSSION}

Periodontitis crop ups when the plaque microorganisms interact with the host defense mechanism. Majority of infiltrating contains mononuclear cells, mainly transmigrated mononuclear phagocytes and lymphocytes [6]. In established periodontitis lesions, the major tissue destruction results from the recruitment of host defense cells via activation of monocytes/macrophages, fibroblasts, lymphocytes, and other cell types [7].

Time-honored periodontal diagnostic parameters like probing depths, bleeding on probing, clinical attachment levels, plaque index, and radiographs assessing alveolar bone level, all these had their ableness and paucities. Moreover inherently limited in only disease history, but not current disease status can be assessed. These traditional measures reveal the damage from past episodes of destruction and require a 2- to 3-mm threshold change before a site can be identified. Advances in oral and periodontal disease diagnostic research are moving toward methods whereby periodontal risk can be identified and quantified by objective measures such as biomarkers [8]. 
Table 3. Comparison between two groups at baseline

\begin{tabular}{|c|c|c|c|c|c|c|}
\hline Baseline & Number & $\begin{array}{l}\text { Mean } \pm \text { standard } \\
\text { deviation }\end{array}$ & $\begin{array}{c}\text { Mean difference } \\
\text { (95\% confidence interval) }\end{array}$ & $t$ & $\begin{array}{l}\text { Degrees of } \\
\text { freedom }\end{array}$ & $P$ value \\
\hline Urine ( $\mu \mathrm{mol} / \mathrm{mol}$; creatinine) & & & $86.31(40.35-132.27)$ & 3.84 & 28 & $0.001^{\mathrm{a}}$ \\
\hline Premenopausal & 15 & $304.91 \pm 60.92$ & & & & \\
\hline Postmenopausal & 15 & $391.22 \pm 61.98$ & & & & \\
\hline Saliva (nmol/L) & & & $1.97(0.71-3.24)$ & 3.20 & 28 & $0.003^{\mathrm{a}}$ \\
\hline Premenopausal & 15 & $13.63 \pm 1.55$ & & & & \\
\hline Postmenopausal & 15 & $15.61 \pm 1.83$ & & & & \\
\hline Plasma (nmol/L) & & & $1.80(0.25-3.35)$ & 2.38 & 28 & $0.02^{\mathrm{a}}$ \\
\hline Premenopausal & 15 & $11.72 \pm 1.51$ & & & & \\
\hline Postmenopausal & 15 & $13.52 \pm 2.51$ & & & & \\
\hline
\end{tabular}

Independent sample $t$ test.

${ }^{a} P<0.05$ is statistically significant.

Table 4. Comparison between two groups at 3 months

\begin{tabular}{|c|c|c|c|c|c|c|}
\hline 3 months & Number & $\begin{array}{l}\text { Mean } \pm \text { standard } \\
\text { deviation }\end{array}$ & $\begin{array}{c}\text { Mean difference } \\
\text { (95\% confidence interval) }\end{array}$ & $t$ & $\begin{array}{l}\text { Degrees of } \\
\text { freedom }\end{array}$ & $P$ value \\
\hline Urine ( $\mu \mathrm{mol} / \mathrm{mol}$; creatinine) & & & $24.88(-15.16-64.92)$ & 1.27 & 28 & 0.21 \\
\hline Premenopausal & 15 & $265.57 \pm 54.57$ & & & & \\
\hline Postmenopausal & 15 & $290.45 \pm 52.48$ & & & & \\
\hline Saliva (nmol/L) & & & $0.35(-0.64-1.34)$ & 0.73 & 28 & 0.47 \\
\hline Premenopausal & 15 & $6.69 \pm 1.24$ & & & & \\
\hline Postmenopausal & 15 & $7.05 \pm 1.41$ & & & & \\
\hline Plasma (nmol/L) & & & $0.28(-0.48-1.05)$ & 0.75 & 28 & 0.46 \\
\hline Premenopausal & 15 & $6.95 \pm 0.95$ & & & & \\
\hline Postmenopausal & 15 & $7.23 \pm 1.09$ & & & & \\
\hline
\end{tabular}

Independent sample $t$ test. $P<0.05$ is statistically significant.

Table 5. Intergroup comparison of change from baseline to 3 months

\begin{tabular}{|c|c|c|c|c|c|c|}
\hline Change from baseline to 3 months & Number & $\begin{array}{l}\text { Mean } \pm \text { standard } \\
\text { deviation }\end{array}$ & $\begin{array}{c}\text { Mean difference } \\
\text { (95\% confidence interval) }\end{array}$ & $t$ & $\begin{array}{l}\text { Degrees of } \\
\text { freedom }\end{array}$ & $P$ value \\
\hline Urine ( $\mu \mathrm{mol} / \mathrm{mol}$; creatinine) & & & $61.43(0.45-122.40)$ & 2.06 & 28 & $0.048^{\mathrm{a}}$ \\
\hline Premenopausal & 15 & $39.34 \pm 63.90$ & & & & \\
\hline Postmenopausal & 15 & $100.77 \pm 95.96$ & & & & \\
\hline Saliva (nmol/L) & & & $1.62(0.05-3.20)$ & 2.11 & 28 & $0.04^{\mathrm{a}}$ \\
\hline Premenopausal & 15 & $6.93 \pm 2.27$ & & & & \\
\hline Postmenopausal & 15 & $8.56 \pm 1.92$ & & & & \\
\hline Plasma (nmol/L) & & & $1.52(-0.04-3.08)$ & 1.99 & 28 & 0.056 \\
\hline Premenopausal & 15 & $4.77 \pm 1.80$ & & & & \\
\hline Postmenopausal & 15 & $6.29 \pm 2.33$ & & & & \\
\hline
\end{tabular}

Independent sample $t$ test.

${ }^{a} P<0.05$ is statistically significant. 


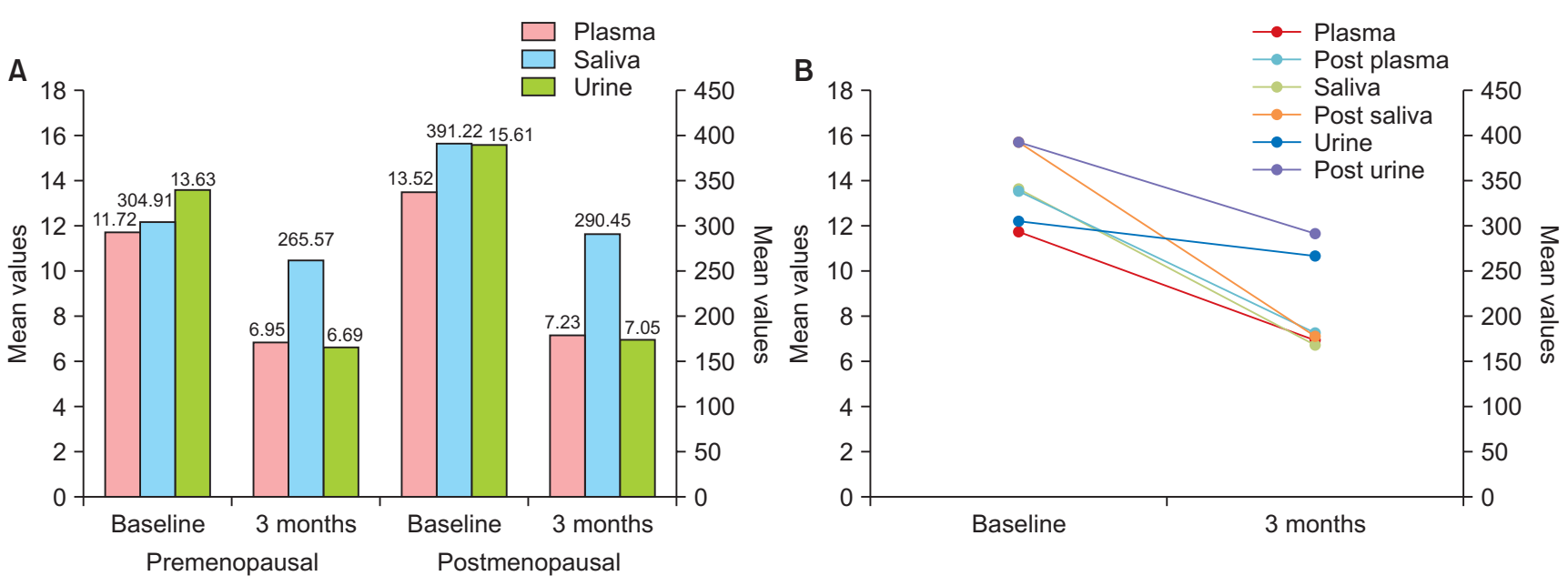

Fig. 2. Comparison of all parameters in both the groups at baseline and 3 months. (A) Neopterin values. (B) Neopterin: pre- and postmenopausal.

As research proving that periodontitis amelioration is multifactorial in provenience. Not even that the diversified bacteria found is site-specific. A series of molecular techniques were developed, including DNA hybridization, polymerase chain reaction and the genomic hybridization techniques, but these also have their own merits and demerits to quantifying the bacteria. As a result, one of the major challenges in the field of periodontology is to determine biomarkers for screening and predicting the early onset of periodontitis or evaluating disease activity and the efficacy of therapy (diagnostic or prognostic tests) has come into the picture [9]. Many studies and many authors stated that deficiency of estradiol hormones has many untoward effects on the overall body along with gingiva. These hormones may effect on soft tissues as well as on hard tissues like bone. Some exemplifications of those studies are the alterations of immunologic responses, including antigen presentation and expression of apoptotic factors, ultimately leading to cell death [10]. Excess stimulation and production of an inflammatory mediator like prostaglandin E2 and intensification of polymorphonuclear leukocytes along with enhanced chemotaxis in the gingival sulcus were heightened by progesterone [11]. Progesterone has also been shown to down-regulate Interleukin (IL)-6 production by human gingival fibroblasts to $50 \%$ of that of control values [12]. Cyto differentiation of stratified squamous epithelium, as well as the synthesis and maintenance of fibrous collagen, has been supremacy by estrogen. Due to hormones action on these cells, the propensity of the epithelial barrier action to bacterial insult and deterioration of defense and repair actions of collagen will be marked-up [13]. Both estrogen and progesterone together have effects on the microcirculatory system during menopause and produce the concomitant effects like endothelial cells and periocytes of the venules swelling, granulocytes and platelets adherence to vessel walls, micro thrombi formation, perivascular mast cells disruption, intensified vascular permeability, and vascular proliferation [14].

In this article, pre- and postmenopause were compared because many proven studies were stating that there are many diversified actions and reactions of menopause on the overall body along with the oral cavity. The extent of severity is distinct in both. For instance, the oral mucosal neural system can be overwhelmed directly by estrogen and thus alter the menopausal women's periodontal health [15]. Low flow rates of saliva will be seen in postmenopausal women than the menstruating women [16]. Periodontal diseases are more often seen in post-menopausal women in a more scathing form, because of the reason for which might be the varying levels of hormones and their effect on the estrogen receptors in fibroblasts and osteoblasts of periodontal tissues [17]. Scardina and Messina [18] examined oral microcirculation in 27 postmenopausal women using video capilloscopy and compared it with controls. Significant differences were found in vascular parameters between cases and controls like loops diameter, vessels tortuosity in labial mucosa and periodontal mucosa density was changed in view of predisposed to inflammation [18]. The ingrained studies have stated that a low systemic inflammatory status was associated 
with the onset of menopause and slowly the inflammatory condition increases with the downturn of hormones associated with menopause and increased serum levels of proinflammatory cytokines IL-1, IL-6, or tumor necrosis factor $\alpha$ in postmenopause women [1922]. Osteopenia was more common in premenopausal women than postmenopausal women. But remarkably osteoporosis was more prevalent in postmenopausal women. It symbolizes that the negatively affect bone mass consistently persist in premenopausal as well as postmenopausal period. These factors were combined with estrogen deficiency after the attainment of menopause and then made these women more osteoporotic [23].

In this study, saliva, plasma, and urine were used as diagnostic media. Dialectics behind was unstimulated saliva was used because saliva is a clinically descriptive, biological fluid (bio fluid). That is valuable for novel approaches to prognosis, laboratory or clinical diagnosis, and keeps track of the management of patients with both oral and systemic diseases. It is readily collected and preserves until process and ideal for early detection of disease as it contains distinguishing soluble biological markers (biomarkers). Saliva encompasses multiple biomarkers which make it useful for multiplexed assays. The unstimulated whole saliva is often used in diagnostics as it contains concentrated biomarkers which can easily detectable during assays [24-27].

Plasma was examined because the availability of biomarkers for the diagnosis of oral and systemic diseases, since most of the biomarkers present in saliva and urine can also be detected in blood. But this statement is not always true in case of conjugated steroid hormones; these salivary levels do not correlate with serum. Contrastingly when analyzing glucose or dehydroepiandrosterone sulfate, one must determine saliva/ plasma ratio. The reason for this discrepancy appears to be the route of entry of the hormone into the oral cavity. Quite a few studies gave positive correlation results with plasma and neopterin [28-31].

Urine samples particularly early morning first dropouts were collected, considering that it gives valuable accurate values and furthermore because of more concentration, abnormalities can easily be detected. And moreover comparatively free of dietary influences and physical activity changes [32]. As neopterin is eliminated by the kidney, changes in the concentration of neopterin in serum are usually reflected by urine levels. As a matter of fact, there is an equivalent responsiveness of neopterin appraisal either in serum or urine [33,34]. The neopterin levels in the body fluids such as serum and urine are increased in some of the diseases which are linked with cellular immune reaction [35].

In this study, three biological fluids saliva, plasma and urine neopterin levels were compared in pre- and postmenopausal women at baseline and three months after NSPT. When we compared individual groups' significant reduction of all the parameters from baseline to 3 months after NSPT was found. And at the same time when compared to two groups only saliva and urine levels were significantly reduced. But plasma reduction was insignificant. These study results are partially supporting and partially contradicting the study done by Cioffi et al. [19] when they compared neopterin gingival crevicular fluid (GCF), saliva and urine in aggressive periodontitis patients, found that significant difference in saliva and insignificant results in urine were found. Pradeep et al. [36] found increased neopterin GCF levels in periodontitis patients compared to healthy individuals. Arjunkumar et al. [37] also got the same results in GCF. Mahendra et al. [38] found same results when compared in saliva, indicating that neopterin levels increase in inflammatory conditions

Prasanna et al. [39] compared salivary neopterin levels in menopausal groups and its effect on periodontal therapy. They found a statistical significant reduction in premenopausal group compared to postmenopause. The present study results are also supporting the above study results. Finally to conclude this periodontitis and menopausal conditions both are inflammatory in nature, when compared three biological fluids neopterin levels before and after periodontal treatment in combination of these two diseases significant reduction after treatment was seen in the premenopausal group compared to postmenopausal group.

Limitations of this study, duration of the postmenopausal period were not standardized. Our study did not directly relate saliva, plasma, and urinary neopterin levels with observed monocyte or macrophage activation.

Periodontal diseases can hit where one lives at any stage of life, but it is quite common among adults. Women are notably more susceptible to periodontal diseases at specific stages of life, exclusively during menopause and postmenopause. Biomarkers play a paramount role in life sciences and have a preeminent role in diagnosis, monitoring of therapy outcomes, and drug discovery. The challenge for biomarkers is to al- 
low prior detection of disease progression and more booming therapy efficacy measurements. For biomarkers to understand their rightful role in routine practice, it is a prerequisite that their relation to the mechanism of disease progression and therapeutic intervention be more fully understood. Measuring the biomarkers from biological fluids may easily identify the prior indication of disease entity and can also prevent the disease severity by preceding the treatment plan. Considering, periodontal therapy is a paragon of excellence to reduce the inflammatory components among all the body parts, if we consider this as a treatment strategy then the future burden of the malady will be in harmony.

\section{ACKNOWLEDGMENTS}

We thank Hema duttukuri and Shilpa Akula for helping in manuscript preparation.

\section{CONFLICT OF INTEREST}

No potential conflict of interest relevant to this article was reported.

\section{REFERENCES}

1. Cekici A, Kantarci A, Hasturk H, Van Dyke TE. Inflammatory and immune pathways in the pathogenesis of periodontal disease. Periodontol 2000 2014; 64: 57-80.

2. Taba M Jr, Kinney J, Kim AS, Giannobile WV. Diagnostic biomarkers for oral and periodontal diseases. Dent Clin North Am 2005; 49: 551-71, vi.

3. Prasanna JS, Sumadhura C, Karunakar P. Neopterin as a diagnostic biomarker for diagnosis of inflammatory diseases like periodontitis. J Oral Res Rev 2017; 9: 45-9.

4. Ozmeriç N, Baydar T, Bodur A, Engin AB, Uraz A, Eren K, et al. Level of neopterin, a marker of immune cell activation in gingival crevicular fluid, saliva, and urine in patients with aggressive periodontitis. J Periodontol 2002; 73: 720-5

5. Wiebe CB, Putnins EE. The periodontal disease classification system of the American Academy of Periodontology--an update. J Can Dent Assoc 2000; 66: 594-7.

6. Terheyden H, Stadlinger B, Sanz M, Garbe AI, Meyle J. Inflammatory reaction - communication of cells. Clin Oral Implants Res 2014; 25: 399-407.

7. Silva N, Abusleme L, Bravo D, Dutzan N, Garcia-Sesnich J, Vernal $\mathrm{R}$, et al. Host response mechanisms in periodontal diseases. J Appl Oral Sci 2015; 23: 329-55.

8. Glick M. The curious life of the biomarker. J Am Dent Assoc 2013;
144: $126-8$.

9. Tomás I, Regueira-Iglesias A, López M, Arias-Bujanda N, Novoa L, Balsa-Castro C, et al. Quantification by qPCR of pathobionts in chronic periodontitis: development of predictive models of disease severity at site-specific level. Front Microbiol 2017; 8: 1443.

10. Jafri Z, Bhardwaj A, Sawai M, Sultan N. Influence of female sex hormones on periodontium: a case series. J Nat Sci Biol Med 2015; 6 (Suppl 1): S146-9.

11. Markou E, Boura E, Tsalikis L, Deligianidis A, Konstantinidis A. The influence of sex hormones on proinflammatory cytokines in gingiva of periodontally healthy premenopausal women. J Periodontal Res 2011; 46: 528-32.

12. Gordon CM, LeBoff MS, Glowacki J. Adrenal and gonadal steroids inhibit IL-6 secretion by human marrow cells. Cytokine 2001; 16: 178-86.

13. Güncü GN, Tözüm TF, Cağlayan F. Effects of endogenous sex hormones on the periodontium--review of literature. Aust Dent J 2005; 50: 138-45.

14. Mutneja P, Dhawan P, Raina A, Sharma G. Menopause and the oral cavity. Indian J Endocrinol Metab 2012; 16: 548-51.

15. Cao M, Shu L, Li J, Su J, Zhang W, Wang Q, et al. The expression of estrogen receptors and the effects of estrogen on human periodontal ligament cells. Methods Find Exp Clin Pharmacol 2007; 29: 329-35.

16. Minicucci EM, Pires RB, Vieira RA, Miot HA, Sposto MR. Assessing the impact of menopause on salivary flow and xerostomia. Aust Dent J 2013; 58: 230-4.

17. Yalcin F, Gurgan S, Gul G. Oral health in postmenopausal Turkish women. Oral Health Prev Dent 2006; 4: 227-33.

18. Scardina GA, Messina P. Oral microcirculation in post-menopause: a possible correlation with periodontitis. Gerodontology 2012; 29: e1045-51.

19. Cioffi M, Esposito K, Vietri MT, Gazzerro P, D'Auria A, Ardovino I, et al. Cytokine pattern in postmenopause. Maturitas 2002; 41: 18792.

20. Yasui T, Uemura H, Tomita J, Miyatani Y, Yamada M, Kuwahara A, et al. Association of interleukin-8 with hot flashes in premenopausal, perimenopausal, and postmenopausal women and bilateral oophorectomized women. J Clin Endocrinol Metab 2006; 91 : 4805-8.

21. Su HI, Freeman EW. Hormone changes associated with the menopausal transition. Minerva Ginecol 2009; 61: 483-9.

22. Malutan AM, Dan M, Nicolae C, Carmen M. Proinflammatory and anti-inflammatory cytokine changes related to menopause. Prz Menopauzalny 2014; 13: 162-8.

23. Mittal S, Kumar A, Gupta RK, Kapoor S, Gulati P, Shukla DK. Comparison of bone mineral density and its variables between premenopausal and postmenopausal women. J Obstet Gynaecol India 2011; 61: 200-4. 
24. Corstjens P, Malamud D. Point-of-care diagnostics for infectious diseases. In: Wong DT, editor. Salivary diagnostics. Ames: WileyBlackwell; 2008. pp.136-49.

25. Farnaud SJ, Kosti O, Getting SJ, Renshaw D. Saliva: physiology and diagnostic potential in health and disease. ScientificWorldJournal 2010; 10: 434-56.

26. Malamud D. Saliva as a diagnostic fluid. Dent Clin North Am 2011; 55: 159-78.

27. Yoshizawa JM, Schafer CA, Schafer JJ, Farrell JJ, Paster BJ, Wong DT. Salivary biomarkers: toward future clinical and diagnostic utilities. Clin Microbiol Rev 2013; 26: 781-91.

28. Barnes VM, Kennedy AD, Panagakos F, Devizio W, Trivedi HM, Jönsson T, et al. Global metabolomic analysis of human saliva and plasma from healthy and diabetic subjects, with and without periodontal disease. PLoS One 2014; 9: e105181.

29. Zhao HX, Yin SS, Fan JG. High plasma neopterin levels in Chinese children with autism spectrum disorders. Int J Dev Neurosci 2015; 41: 92-7.

30. Yamamoto E, Hirata Y, Tokitsu T, Kusaka H, Tabata N, Tsujita K, et al. The clinical significance of plasma neopterin in heart failure with preserved left ventricular ejection fraction. ESC Heart Fail 2016; 3: 53-9.

31. Raheja UK, Fuchs D, Lowry CA, Stephens SH, Pavlovich MA, Mohyuddin $\mathrm{H}$, et al. Heritability of plasma neopterin levels in the Old Order Amish. J Neuroimmunol 2017; 307: 37-41.

32. Kalantari S, Jafari A, Moradpoor R, Ghasemi E, Khalkhal E. Hu- man urine proteomics: analytical techniques and clinical applications in renal diseases. Int J Proteomics 2015; 2015: 782798.

33. Behringer V, Stevens JM, Leendertz FH, Hohmann G, Deschner T. Validation of a method for the assessment of urinary neopterin levels to monitor health status in non-human-primate species. Front Physiol 2017; 8: 51.

34. Werner ER, Bichler A, Daxenbichler G, Fuchs D, Fuith LC, Hausen $A$, et al. Determination of neopterin in serum and urine. Clin Chem 1987; 33: 62-6.

35. Murr C, Widner B, Wirleitner B, Fuchs D. Neopterin as a marker for immune system activation. Curr Drug Metab 2002; 3: 175-87.

36. Pradeep AR, Kumar MS, Ramachandraprasad MV, Shikha C. Gingival crevicular fluid levels of neopterin in healthy subjects and in patients with different periodontal diseases. J Periodontol 2007; 78: 1962-7.

37. Arjunkumar R, Sudhakar U, Jayakumar P, Arunachalam L, Suresh S, Virupapuram P. Comparative analysis of gingival crevicular fluid neopterin levels in health and periodontal disease: a biochemical study. Indian J Dent Res 2013; 24: 582-6.

38. Mahendra L, Mahendra J, Borra SK, Nagarajan A. Estimation of salivary neopterin in chronic periodontitis. Indian J Dent Res 2014; 25: 794-6.

39. Prasanna JS, Sumadhura C, Karunakar P, Rohini N. Comparative evaluation of salivary neopterin levels and its effects to periodontal therapy in pre- and post-menopausal women. J Menopausal Med 2017; 23: 32-41. 